\title{
COVID-19 Outbreak: Routes of Transmission, Precautions, and Economic Impact on Dentistry-A Review Article
}

\author{
Mohammed Tahir Abdalqadir \\ Department of Prosthodontics \\ College of Dentistry \\ University of Sulaiman \\ Sulaimani, Iraq \\ Mohammed.Abdalqadir@univsul.edu.iq
}

Article Info
$\begin{aligned} & \text { Special Issue on } \\ & \text { Coronavirus ( COVID- } \\ & \text { 19) }\end{aligned}$

DOI: $10.24017 /$ covid.3

Received : 28 April 2020

Accepted : 01 May 2020

\section{Keywords:}

COVID-19,

Dentistry,

Coronavirus,

SARS-CoV-2,

Transmission,

Economy

\begin{abstract}
In late 2019, a novel coronavirus appeared in Wuhan, Hubei province, China, and then rapidly spread around the world. The virus produces severe and even fatal pneumonia; the most common clinical symptoms among infected persons include fever, shortness of breath, cough, fatigue, and abnormal chest CT. Though the virus first traveled from animal to human, it can now spread from human to human through direct transmission such as coughing, sneezing, and inhalation of droplets; and through contact with mucus membranes of oral, nasal, and eye. COVID-19 also can be transmitted through saliva and the fecaloral route. The risk of cross-infection between patients and dental practitioners is high due to the nature of dental work, so this outbreak has made a powerful impact, both medically and economically, on the dentistry sector. Dental practitioners should have comprehensive knowledge of the virus and its route of transmission, and they should take proper precautions during dental treatments to protect themselves and their patients. This article provides a review of COVID-19, its transmission routes, necessary precautions during dental setting, and the virus's impact on the economy of the dental industry.
\end{abstract}

Copyright (0) 2020 Kurdistan Journal of Applied Research. All rights reserved.

\section{INTRODUCTION}

In December 2019, a new pneumonia outbreak with an unspecified etiology originated in Wuhan, Hubei province, China. The majority of the cases were bound to a Hunan local seafood market buying and selling live animals; this commonality suggested that the pathogen had been transmitted from animals-to-humans and had quickly escalated to human-to-human transmission. This pneumonia-like infection quickly spread to most of other provinces from 
Wuhan, and today, 212 countries and territories around the world have reported more than 3,305000 confirmed cases of the COVID-19 and more than 235,000 deaths [1-4].

The most common clinical symptoms among infected patients include dry cough, shortness of breath, fever, atypical chest CT, and fatigue. In addition, less common symptoms include headache, diarrhea, sputum, and hemoptysis [5-7].

A novel coronavirus was formally reported as the causative pathogen of COVID-19 on January 8, 2020, by the Chinese Center for Disease Control and Prevention, and this disease has since become a severe public health problem both in China and the rest of the world $[8,9]$. The World Health Organization (WHO), on January 30, 2020, announced that the COVID-19 outbreak was a public health emergency of international concern [10].

The novel coronavirus was first called $2019-\mathrm{nCoV}$ and was then officially named severe acute respiratory syndrome coronavirus 2 (SARS-CoV-2). The WHO, on February 11, 2020, announced COVID-19 as the official name for this new viral pneumonia disease, while the International Committee on Taxonomy of Viruses (ICTV) named the novel coronavirus SARS-CoV-2 [11-13]. Certain demographics are more susceptible to contracting COVID-19; the infection is most contagious among people, particularly men, aged 65 years and above; healthcare staff treating patients with COVID-19; individuals with liver and kidney failure; patients with immunodeficiency; and individuals who have close contact with patients in clinical settings $[14,15]$.

The risk of cross-infection between dental patients and practitioners may be high because of the nature of the dental setting. It is urgent that dental practitioners in countries and regions affected by COVID-19 apply effective and strict infection control protocols. This article provides a thorough review of the COVID-19 outbreak and its relation to and impact on dentistry.

\section{LITERATURE REVIEW}

\subsection{What Is Covid-19?}

Coronaviruses are minute in size, about $65-125 \mathrm{~nm}$ in diameter, and they are a member of the Coronaviridae family in the Nidovirales order, composed of a single-strand RNA molecule as a nucleic genome material ranging in size from 26-32 kb in length [16-18]. COVID-19, which emerged in Wuhan, China, belongs to the $\beta-\mathrm{CoV}$ (Betacoronavirus) genus according to the phylogenetic analysis of the viral genome [19,20].

According to a recent study, SARS-CoV-2 is zoonotic, similar to Sever Acute Respiratory Syndrome (SARS-CoV) and Middle East Respiratory Syndrome (MERS-CoV). The most probable origin is Chinese horseshoe bats (Rhinolophus sinicus), and the intermediate host most likely is the pangolin $[14,21,22]$.

The structure of COVID-19 is a mutated form. The genome of the virus encodes four important structural proteins, as shown in Figure 1: spike (S) glycoprotein, membrane (M) protein, envelope (E) protein, and hemagglutinin esterase (HEs) [23-25].

The $S$ protein from the coronavirus promotes viral-host cell fusion and facilitates viral entry into target cells [26-29].

The $\mathrm{M}$ protein helps viral envelope formation, confirms the nucleocapsid stability, interacts with other structural proteins of the coronavirus, encourages viral gathering, and encapsulates the genetic materials of the virus [30-32].

The smallest E protein involves in virion envelope inside the infected cells [33]. There is another protein known as $\mathrm{N}$ protein that helps in the replication process and can bind to the genome of the virus to form an N protein-RNA complex called a nucleocapsid [34, 35]. The HEs protein envelopes glycoproteins and mediates attachment to O-acetylated sialic acids [36]. 


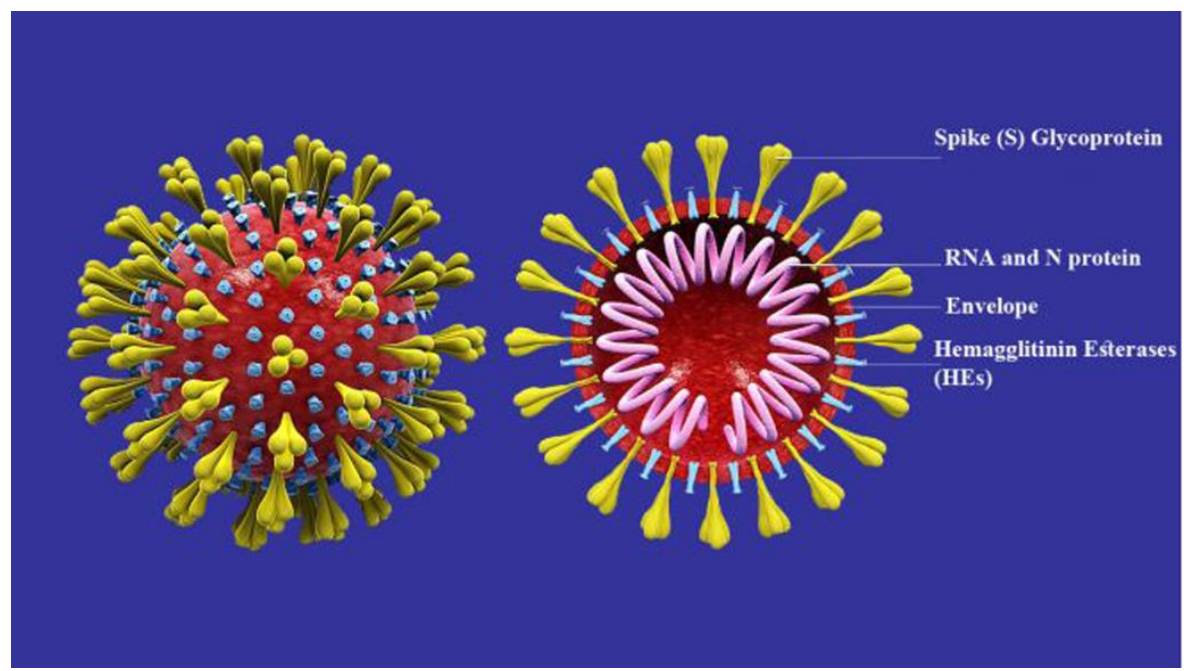

Figure 1: The structural characteristics of Coronavirus [37]

\section{2 transmission routes of covid-19}

COVID-19 can be transmitted through direct transmission like a sneeze, a cough, or inhalation of droplets or through contact with oral, nasal, or ocular mucous membranes [2]. The disease also can be directly or indirectly transmitted through saliva [38]. COVID-19 may be transmitted through aerosols formed during medical procedures [39]. There may be a risk of transmission of the virus through the fecal-oral route, as researchers identified COVID-19 in the stool of patients from the United States and China [40]. A study revealed that SARS-CoV2 could be spread from mothers to their newborns (vertical transmission) [41]. There is a report of one case of COVID-19 infection in Germany showed that transmission could occur through contact with asymptomatic patients [42].

\section{3 transmission routes of covid-19 in dental practice}

A report published by The New York Times on March 15, 2020, entitled "The Workers Who Face the Greatest Coronavirus Risk" revealed that dentists are the workers most susceptible to the risk of contracting COVID-19, even more susceptible than general physicians and nurses are [43]. When a person talks, coughs, laughs, or sneezes, aerosols and droplets are generated ranging from large ( $>5 \mu \mathrm{m}$ diameter) to small ( $\leq 5 \mu \mathrm{m}$ diameter). While larger particles quickly fall to the ground because of gravity, necessitating close physical proximity between an infected person and others for transmission to occur, smaller droplets can remain for a prolonged time in the air and travel farther before contaminating surfaces or entering the respiratory tract [44]. Results from one study showed that aerosols from highly virulent pathogens like SARS-CoV could travel more than two meters [45]. One study reported that the air of the dental office contains 38 types of microorganisms [46], and To et al. reported the presence of live coronaviruses in the saliva of infected persons by viral culture method [38]. COVID-19 uses ACE2 as a receptor to invade cells, and ACE2 receptors in epithelial cells of salivary gland ducts were shown to be a prime target of SARS-CoV-2 infection [20, 47]. Dental practitioners and patients are at high risk of exposure to pathogenic microorganisms, including COVID-19, because of the nature of dental work, which involves persistent exposure to blood, saliva, and other body fluids, face-to-face communication with patients, and handling sharp instruments. COVID-19 in dental settings can be transmitted through inhalation of the virus while airborne; direct contact with oral fluids and blood; contact between droplets or aerosols containing the virus and the oral, nasal, and conjunctival mucosa; and through indirect contact with contaminated surfaces and instruments [47-49]. An epidemiological study showed that COVID-19 has superior transmissibility than SARS-CoV and MERS-CoV have [49]. The infectious COVID-19 could be spread through any of the above conditions in dental clinics and hospitals, as shown in Figure 2. 


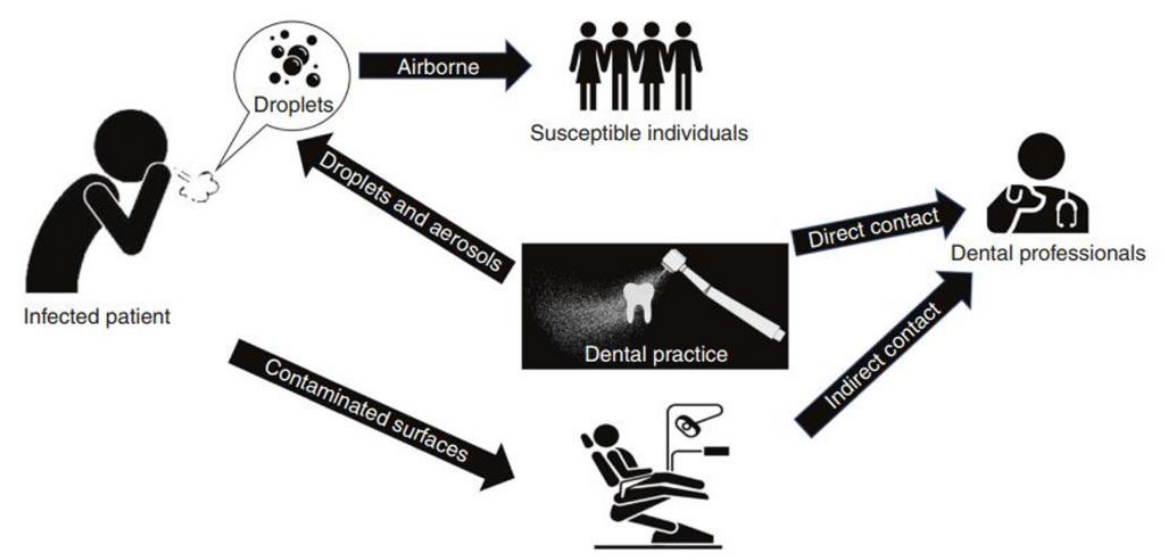

Figure 2: Transmission routes of COVID-19 in dental clinics [50]

\section{4 precautions in dental practice and dental clinics}

During this 2019-nCoV epidemic, patients who are suspected to have COVID-19 should not be treated in dental clinics; instead, dentists must quarantine the patients and inform the control department in the shortest time as possible. The body temperature measurement of patients is strongly recommended using a contact-free forehead thermometer. Each patient should be asked to report any fever, respiratory symptoms like cough and shortness of breath, history of travel to a suspected country or region, recent contact with people who have traveled to a suspected country or region, or participation in any meeting or gathering in the past two weeks. If the patient replies "yes" to any of the above questions and the patient's body temperature is below $37.3^{\circ} \mathrm{C}$, dental treatments should be postponed until 14 days after the exposure. If the patient replies "yes" and the body temperature is above $37.3^{\circ} \mathrm{C}$, then the patient should be quickly quarantined, and the dentist should contact the local health department or infection control department. If the patient replies "no" and the body temperature is above $37.3{ }^{\circ} \mathrm{C}$, then instruction should be given to the patient to go to specialized clinics for COVID-19 for further medical care [50].

The following precautions should be used during dental treatments, especially emergency cases, because of the high transmissibility of COVID-19:

\subsection{1 waiting area/reception area}

All patients in the reception area should use masks and gloves; when coughing or sneezing, they must use a tissue or their elbow to cover their nose and mouth, quickly put the tissues used into the waste bin, and ensure hand hygiene. The distance between two patients in the waiting area should be at least $1 \mathrm{~m}$ [1]. The waiting area should have adequate ventilation: a room with natural ventilation with a capacity of $60 \mathrm{~L} / \mathrm{s}$ per patient can be considered as proper ventilation [51].

\subsection{2 hand hygiene}

Hand washing has a crucial role in preventing infections, and recently there is an increasing in awareness of the value of hand washing in the prevention of acute respiratory infections. Epidemiological studies showed that washing hands with soap and water; and 70-90\% alcohol-based hand rubs was effective in suppressing SARS-CoV transmission [52, 53].

The WHO reports that hand hygiene either with soap and water or with an alcohol-based hand rub are equally effective. When the hands are not visibly dirty, an alcohol-based hand rub is preferred, but when the hands are visibly soiled, soap and water must be used [54].

The WHO suggests that hand hygiene should be performed before the aseptic procedure, before touching a patient, after touching a patient, after exposure to bodily fluid, and after touching a patient's surroundings [55]. 


\subsection{3 personal protective measures}

Dentists are more prone to infection and transmission of oral microorganisms, especially to the inner part of the eye and nose, during dental procedures; the eye and the nose are essential areas for transmission of infection due to proximity between the dentist and the patients [56, 57]. Airborne droplets are the primary means for the transmission of COVID-19, so the use of barrier protection measures like masks, gloves, eyewear, face shields, caps, and other types of protective wear is strongly recommended for all dentists and other healthcare providers in hospitals and clinics during this epidemic.

\subsection{4 mouth rinse before dental treatments}

An effective way of decreasing the number of microorganisms in oral aerosols is the mouth rinse before dental treatments [58, 59]. A study reported that the use of a mouth rinse containing chlorhexidine, cetylpyridinium, and essential oils before the dental procedures resulted in a decrease in the formation of colony units in dental aerosol by $68.4 \%[59,60]$. Chlorhexidine showed activity against several viruses, including human immunodeficiency virus (HIV), herpes simplex virus (HSV), and hepatitis B virus (HBV) [61], but it may not be effective against 2019-nCoV. Mouthwashes that contain $1 \%$ hydrogen peroxide or $0.2 \%$ povidone as an oxidative agent can reduce the oral microbes in saliva, including COVID-19, because 2019-nCoV is vulnerable to oxidation [50].

\subsection{5 use of rubber dam isolation}

The application of rubber dams can reduce saliva and blood-contaminated aerosols especially when ultrasonic devices and high-speed handpieces are used, and these dams can get rid all pathogens rising from respiratory secretion. If the rubber dam is placed and used correctly, the tooth that is undergoing treatment would be the only source of contamination [62]. The use of rubber dam could importantly minimize airborne particles in the operational field by $70 \%$ [63] and reduce the spread of microorganisms by $90 \%$ [64]. When the application of a rubber dam is not possible, the four-handed operation should be used, and the use of manual devices like a hand scaler and Carisolv are recommended for periodontal scaling and caries removal to reduce the generation of aerosols [50].

\subsection{6 use of anti-retraction handpiece}

The use of a high-speed dental handpiece with anti-retraction can decrease the backflow of the hepatitis B virus and oral bacteria into the tube of the dental handpiece far more efficiently than a dental handpiece without anti-retraction property can [65]. During this COVID-19 outbreak, the use of an anti-retraction handpiece, especially one with anti-retractive valves, is recommended, and handpieces without anti-retraction vales should be avoided as an additional preventive step to prevent cross-infection of COVID-19 [50].

\subsection{7 disinfection of surfaces}

The aerosols and droplets that are generated during dental procedures contain infective microorganisms and can be deposited on nearby devices and surfaces. A study showed that exposure of coronaviruses to $0.1 \%$ sodium hypochlorite, $0.5 \%$ hydrogen peroxide, and 62 $71 \%$ ethanol can significantly reduce their viral infectivity, and this helps to prevent further spread of the virus [48]. Therefore, disinfection of devices and surfaces, especially surfaces in close contact with the operating areas, is essential. Disinfection and cleaning should include all parts, such as desks, chairs, and door handles, of the waiting areas.

\subsection{8 medical waste management}

All dental waste should be managed appropriately, those items that are reusable should be cleaned, sterilized, and properly stored. Disposable wastes, including protective measures considered as infectious medical waste, should be stored in yellow double-layer medical waste bags with gooseneck ligation and should be disposed of according to the requirements for the manipulation of medical waste [50]. 


\section{5 impact of covid-19 on the dental economy}

Though COVID-19 is a new virus, the WHO has recognized the virus's role in sparking a global pandemic. COVID-19 has strongly affected and slowed down economies worldwide, limited transportation, reduced travel and tourism, shuttered holy places, and dramatically decreased the price of oil. COVID-19 will undoubtedly affect the dental job market and economy; according to a study for 2000, dentistry noted to have more than two million jobs throughout the world, and total spending on dental services was calculated at $\$ 203.6$ billion. Taxes produced directly or indirectly from dental practice totaled more than $\$ 33$ billion, and the annual effect of one additional dentist on the economy was estimated at $\$ 1,278,253$ [66], but these numbers decreased nowadays during COVID-19 outbreak. According to a study in China during the rise of COVID-19, the novel coronavirus was found to significantly influence the use of dental services among the general population. The overall number of dental emergency patients decreased by $38 \%$, and non-urgency cases decreased to three-tenths of pre-COVID-19 rates [67]. In some countries or areas, such as the Kurdistan region of Iraq, there has been a total lockdown of all dental clinics, except for few specialized governmental hospitals for treating emergency cases using the above precautions, for more than a month. The lockdown and decrease in patients seeking dental services will continue to have a negative impact on the dental economy.

\section{CONCLUSION}

The emergence of COVID-19 has proven to be a challenge and responsibility for dentists because dentists have a high chance of exposure to infectious diseases. A good understanding of COVID-19, its risks, and routes of transmission, especially in dental clinics, will help to protect dentists and patients alike. Though lockdowns and decreases in dental activities have had a profound effect on the economy of this sector, all the aforementioned precautions should be used during any dental treatment during the COVID-19 epidemic.

\section{REFRENCE}

[1] Z. Ge, L. Yang, J. Xia, X. Fu, and Y. Zhang, "Possible aerosol transmission of COVID-19 and special precautions in dentistry," Journal of Zhejiang University-SCIENCE B (Biomedicine \& Biotechnology),16, 1-8, 2020.

[2] T. Liu et al., "Transmission dynamics of 2019 novel coronavirus (2019-nCoV)," The Lancet, 2020, doi: 10.1101/2020.01.25.919787.

[3] N. Zhu et al., "A novel coronavirus from patients with pneumonia in China, 2019," The New England Journal of Medicine, 382(8), 727-733, 2020

[4] C. Wang, P. W. Horby, F. G. Hayden, and G. F. Gao, "A novel coronavirus outbreak of global health concern," The Lancet, 395(10223), 4703, 2020.

[5] W. Guan et al., "Clinical characteristics of 2019 novel coronavirus infection in China," The New England Journal of Medicine, 2020, doi: 10.1101/2020.02.06.20020974.

[6] C. Huang et al., "Clinical features of patients infected with 2019 novel coronavirus in Wuhan, China," The Lancet, 395(10223), 497-306, 2020.

[7] D. Wang et al., "Clinical Characteristics of 138 Hospitalized Patients with 2019 Novel Coronavirus-Infected Pneumonia in Wuhan, China,” Journal of the American Medical Association, 323(11), 1061-1069, 2020.

[8] Q. Li et al., "Early Transmission Dynamics in Wuhan, China, of Novel Coronavirus-Infected Pneumonia," The New England Journal of Medicine, 382(13), 1199-1207, 2020.

[9] A. L. Phelan, R. Katz, and L. O. Gostin, "The Novel Coronavirus Originating in Wuhan, China: Challenges for Global Health Governance," Journal of the American Medical Association, 323(8), 709-710, 2020.

[10] E. Mahase, "China coronavirus: WHO declares international emergency as death toll exceeds 200", British Medical Journal, 2020. doi:10.1136/bmj.m408.

[11] A. E. Gorbalenya, "Severe acute respiratory syndrome-related coronavirus - The species and its viruses, a statement of the Coronavirus Study Group," bioRxiv, 2020, doi: 10.1101/2020.02.07.937862.

[12] J. Guarner, "Three Emerging Coronaviruses in Two Decades: The Story of SARS, MERS, and Now COVID19," American Journal of Clinical Pathology, 395(10228), 420-421, 2020.

[13] S. Jiang et al., "A distinct name is needed for the new coronavirus.," The Lancet (London, England), 395(10228), 949, 2020.

[14] J. F. W. Chan et al., "A familial cluster of pneumonia associated with the 2019 novel coronavirus indicating person-to-person transmission: a study of a family cluster," The Lancet, 395(10223), 514-523, 2020.

[15] N. Chen et al., "Epidemiological and clinical characteristics of 99 cases of 2019 novel coronavirus pneumonia in Wuhan, China: a descriptive study," The Lancet, 395(10223), 507-513, 2020. 
[16] A. R. Fehr and S. Perlman, "Coronaviruses: An overview of their replication and pathogenesis," in Coronaviruses: Methods and Protocols, H. Maier, E. Bickerton, P. Britton, Humana Press, New York, NY, p.123, 2015.

[17] A. E. Gorbalenya, L. Enjuanes, J. Ziebuhr, and E. J. Snijder, "Nidovirales: Evolving the largest RNA virus genome," Virus Research, 117(1), 17-37, 2006.

[18] M. Khan, S. Kazmi, A. Bashir, and N. Siddique, "COVID-19 infection: origin, transmission, and characteristics of human coronaviruses," Journal of Advanced Reearch., 24(2020), 265-269, 2020.

[19] F. Wu et al., "A new coronavirus associated with human respiratory disease in China," Nature, 579(7798), 265$269,2020$.

[20] P. Zhou et al., "A pneumonia outbreak associated with a new coronavirus of probable bat origin," Nature, 579(7798), 270-273, 2020.

[21] R. Lu et al., "Genomic characterisation and epidemiology of 2019 novel coronavirus: implications for virus origins and receptor binding," The Lancet, 395(10224), 565-574, 2020.

[22] L. Wahba et al., "Identification of a pangolin niche for a 2019-nCoV-like coronavirus through an extensive meta-metagenomic search," bioRxiv, 2020, doi: 10.1101/2020.02.08.939660.

[23] E. Mortola and P. Roy, "Efficient assembly and release of SARS coronavirus-like particles by a heterologous expression system," Federation of European Biochemical Societies Leters., 576(1-2), 174-178, 2004.

[24] T. R. Dhama K, Pawaiya RNS, Chakraborty S and V. A. Saminathan M, "Coronavirus infection in equines: a review," Asian Journal of Animal and Vetirnary Advances, 9(3), 164-176, 2014.

[25] C. Wang et al., "MERS-CoV virus-like particles produced in insect cells induce specific humoural and cellular imminity in rhesus macaques," Oncotarget, 8(8), 12686-12694, 2017.

[26] S. Belouzard, J. K. Millet, B. N. Licitra, and G. R. Whittaker, "Mechanisms of coronavirus cell entry mediated by the viral spike protein.," Viruses, 4(6), 1011-1033, 2012.

[27] H. C. Song et al., "Synthesis and Characterization of a Native, Oligomeric Form of Recombinant Severe Acute Respiratory Syndrome Coronavirus Spike Glycoprotein,” Journal of Viroogy., 78(19), 10328-10335, 2004.

[28] Y. L. Siu et al., "The M, E, and N Structural Proteins of the Severe Acute Respiratory Syndrome Coronavirus Are Required for Efficient Assembly, Trafficking, and Release of Virus-Like Particles," Journal of Virology, 82(22), 11318-11330, 2008.

[29] M. P. Hantak, E. Qing, J. T. Earnest, and T. Gallagher, "Tetraspanins: Architects of Viral Entry and Exit Platforms," Journal of Virology, 93(6), e01429-17, 2018

[30] K. L. Siu et al., "Severe acute respiratory syndrome coronavirus M protein inhibits type I interferon production by impeding theformation of TRAF3·TANK·TBK1/IKKe complex," Journal of Biological Chemistry, 284(24), 16202-16209, 2009

[31] B. W. Neuman et al., "A structural analysis of M protein in coronavirus assembly and morphology," Journal of Structural Biology, 174(1), 11-22, 2011.

[32] W. C. Hsin et al., "Nucleocapsid protein-dependent assembly of the RNA packaging signal of Middle East respiratory syndrome coronavirus," Journal of Biomedical Science, 25(1), 47-58, 2018.

[33] A. Ghosh, D. Bhattacharyya, and A. Bhunia, "Structural insights of a self-assembling 9-residue peptide from the C-terminal tail of the SARS corona virus E-protein in DPC and SDS micelles: A combined high and low resolution spectroscopic study," Biochimica et Biophysica Acta-Biomembranes, 1860(2), 335-346, 2018.

[34] Y. Cong et al., "Nucleocapsid Protein Recruitment to Replication-Transcription Complexes Plays a Crucial Role in Coronaviral Life Cycle," Journal of Virology, 94(4), 1-21, 2019.

[35] Y. Chen, Q. Liu, and D. Guo, "Emerging coronaviruses: Genome structure, replication, and pathogenesis," Journal of Medical Virology, 92(4), 418-423, 2020.

[36] Y. H. Li, C. Y. Hu, N. P. Wu, H. P. Yao, and L. J. Li, "Molecular Characteristics, Functions, and Related Pathogenicity of MERS-CoV Proteins," Engineering, 5(5), 940-947, 2019.

[37] File:3D medical animation corona virus.jpg. Wikimedia; January 2020, Available from: https://commons.wikimedia, org/wiki/File:3D_medical_animation_corona_virus.jpg. Accessed 3 March 2020.

[38] K. K.-W. To et al., "Consistent detection of 2019 novel coronavirus in saliva," Clinical Infectious Disease, 2020, doi: 10.1093/cid/ciaa149.

[39] R. S. Wax and M. D. Christian, "Practical recommendations for critical care and anesthesiology teams caring for novel coronavirus (2019-nCoV) patients," Canadian Journal of Anesthesia, 2020, doi: 10.1007/s12630-02001591-x.

[40] M. L. Holshue et al., "First case of 2019 novel coronavirus in the United States," The New England Journal of Medicine, 2020, doi: 10.1056/NEJMoa2001191.

[41] H. Chen et al., "Clinical characteristics and intrauterine vertical transmission potential of COVID-19 infection in nine pregnant women: a retrospective review of medical records," The Lancet, 395(10226), 809-815, 2020.

[42] C. Rothe et al., "Transmission of 2019-NCOV infection from an asymptomatic contact in Germany," The New England Journal of Medicine, 382(10), 970-971, 2020.

[43] L. Gamio, The Workers Who Face the Greatest Coronavirus Risk. The New York Times, Available online: https://www.nytimes.com/interactive/2020/03/15/business/economy/coronavirus-workerrisk.html?action=click\&module=Top+Stories\&pgtype=Homepage (accessed on 15 March 2020).

[44] World Health Organization(WHO), "Infection prevention and control of epidemic- and pandemic-prone acute respiratory infections in health care," WHO, Geneva, Switzerland, 2014.

[45] J. S. Kutter, M. I. Spronken, P. L. Fraaij, R. A. Fouchier, and S. Herfst, "Transmission routes of respiratory viruses among humans," Current Opinion in Virology, 28, 142-151, 2018.

[46] C. Zemouri, H. De Soet, W. Crielaard, and A. Laheij, "A scoping review on bio-Aerosols in healthcare \& the dental environment," PLoS One, 12(5), 1-25, 2017. 
[47] L. Liu et al., "Epithelial Cells Lining Salivary Gland Ducts Are Early Target Cells of Severe Acute Respiratory Syndrome Coronavirus Infection in the Upper Respiratory Tracts of Rhesus Macaques," Journal of Virology, 85(8), 4025-4030, 2011.

[48] G. Kampf, D. Todt, S. Pfaender, and E. Steinmann, "Persistence of coronaviruses on inanimate surfaces and their inactivation with biocidal agents," Journal of Hospital Infection, 104(3), 246-251, 2020.

[49] J. Chen, "Pathogenicity and transmissibility of 2019-nCoV-A quick overview and comparison with other emerging viruses," Microbes and Infection, 22(2), 69-71, 2020.

[50] X. Peng, X. Xu, Y. Li, L. Cheng, X. Zhou, and B. Ren, "Transmission routes of 2019-nCoV and controls in dental practice," International Journal of Oral Science, 12(1), 1-6, 2020.

[51] J. Atkinson, Y. Chartier, C. L. Pessoa-silva, P. Jensen, and Y. Li, Natural Ventilation for Infection Control in Health Care Settings WHO Publication / Guidelines Natural Ventilation for Infection Control in Health-Care Settings Edited by : World Health Organization, Geneva, Switzerland, 2009.

[52] H. F. Rabenau, G. Kampf, J. Cinatl, and H. W. Doerr, "Efficacy of various disinfectants against SARS coronavirus," Journal of Hospital Infection, 61(2), 107-111, 2005.

[53] I. C. H. Fung and S. Cairncross, "Effectiveness of handwashing in preventing SARS: A review," Tropical Medicine and International Health, 11(11), 1749-1758, 2006.

[54] World Health Organization, "Infection prevention and control during halth care when novel coronavirus (nCOV) infection is suspected," WHO, Geneva, Switzerland, 2020c.

[55] World Health Organisation (WHO), "WHO Guidelines on Hand Hygiene in Health Care: First Global Patient Safety Challenge Clean Care Is Safer Care," WHO, Geneva, Switzerland, 2009.

[56] C. D. Bentley, N. W. Burkhart, and J. J. Crawford, "Evaluating spatter and aerosol contamination during dental procedures.," Journal of the American. Dental Association, 125(5), 579-584, 1994.

[57] F. Nejatidanesh, Z. Khosravi, H. Goroohi, H. Badrian, and O. Savabi, "Risk of contamination of different areas of dentist's face during dental practices," International journal of preventive medicine, 4(5), 611-615, 2013.

[58] L. P. Samaranayake and M. Peiris, "Severe acute respiratory syndrome and dentistry: A retrospective view," Journal of the American Dental Association, 135(9), 1292-1302, 2004.

[59] M. Feres, L. C. Figueiredo, M. Faveri, B. Stewart, and W. De Vizio, "The effectiveness of a preprocedural mouthrinse containing cetylpyridiniuir chloride in reducing bacteria in the dental office," Journal of the American Dental Association, 141(4), 415-422, 2010.

[60] V. C. Marui, M. L. S. Souto, E. S. Rovai, G. A. Romito, L. Chambrone, and C. M. Pannuti, "Efficacy of preprocedural mouthrinses in the reduction of microorganisms in aerosol: A systematic review," Journal of the American Dental Association, 150(12), 1015-1026, 2019.

[61] A. Wood and D. Payne, "The action of three antiseptics/disinfectants against enveloped and non-enveloped viruses," Journal of Hospital Infection , 38(4), 283-295, 1998.

[62] S. K. Harrel and J. Molinari, "Aerosols and splatter in dentistry: A brief review of the literature and infection control implications," Journal of the American Dental Association, 135(4), 429-437, 2004.

[63] L. P. Samaranayake, J. Reid, and D. Evans, "The efficacy of rubber dam isolation in reducing atmospheric bacterial contamination.," ASDC Journal of Dentistry for Children, 56(6), 442-444, 1989.

[64] M. A. Cochran, C. H. Miller, and M. A. Sheldrake, "The efficacy of the rubber dam as a barrier to the spread of microorganisms during dental treatment.," Journal of the American Dental Association, 119(1), 141-144, 1989.

[65] T. Hu, G. Li, Y. Zuo, and X. Zhou, "Risk of Hepatitis B Virus Transmission via Dental Handpieces and Evaluation of an Antisuction Device for Prevention of Transmission," Infection Control and Hospital Epidemiology, 28(1), 80-82, 2007

[66] D. R. House, C. L. Fry, and L. J. Brown, "The economic impact of dentistry," Journal of the American Dental Association, 135(3), 347-352, 2004.

[67] H. Guo, Y. Zhou, X. Liu, and J. Tan, "The impact of the COVID-19 epidemic on the utilization of emergency dental services,” Journal of Dental Science, 2020, doi: 10.1016/j.jds.2020.02.002. 